\title{
Choice of artificial insemination beef bulls used to mate with female dairy cattle
}

\author{
D. P. Berry, ${ }^{1 *}$ (1) S. C. Ring, ${ }^{2}$ A. J. Twomey, ${ }^{1}$ and R. D. Evans ${ }^{2}$ \\ ${ }^{1}$ Teagasc, Animal and Grassland Research and Innovation Centre, Moorepark, Fermoy P61 P302, Co. Cork, Ireland \\ ${ }^{2}$ Irish Cattle Breeding Federation, Highfield House, Shinagh, Bandon P72 X050, Co. Cork, Ireland
}

\begin{abstract}
Understanding the preferences of dairy cattle producers when selecting beef bulls for mating can help inform beef breeding programs as well as provide default parameters in mating advice systems. The objective of the present study was to characterize the genetic merit of beef artificial insemination (AI) bulls used in dairy herds, with particular reference to traits associated with both calving performance and carcass merit. The characteristics of the beef AI bulls used were compared with those of the dairy AI bulls used on the same farms. A total of 2,733,524 AI records from 928,437 females in 5,967 Irish dairy herds were used. Sire predicted transmitting ability (PTA) values and associated reliability values for calving performance and carcass traits based on national genetic evaluations from prior to the insemination were used. Fixed effects models were used to relate both genetic merit and the associated reliability of the dairy and beef bulls used on the farm with herd size, the extent of Holstein-Friesian $\times$ Jersey crossbreeding adopted by the herd, whether the herd used a technician insemination service or do-ityourself, and the parity of the female mated. The mean direct calving difficulty PTA of the beef bulls used was 1.85 units higher than that of the dairy bulls but with over 3 times greater variability in the beef bulls. This 1.85 units equates biologically to an expectation of 1.85 more dystocia events per 100 dairy cows mated in the beef $x$ dairy matings. The mean calving difficulty PTA of the dairy AI bulls used reduced with increasing herd size, whereas the mean calving difficulty PTA of the beef AI bulls used increased as herd size increased from 75 cows or fewer to 155 cows; the largest herds $(>155$ cows) used notably easier-calving beef bulls, albeit the calving difficulty PTA of the beef bulls was 3.33 units versus 1.67 units for the dairy bulls used in these herds. Although we found a general tendency for larger herds
\end{abstract}

Received August 8, 2019.

Accepted October 17, 2019

*Corresponding author: donagh.berry@teagasc.ie to use dairy AI bulls with lower reliability, this trend was not obvious in the beef AI bulls used. Irrespective of whether dairy or beef AI bulls were considered, herds that operated more extensive Holstein-Friesian $\times$ Jersey crossbreeding (i.e., more than $50 \%$ crossbred cows) used, on average, easier calving, shorter gestationlength bulls with lighter expected progeny carcasses of poorer conformation. Mean calving difficulty PTA of dairy bulls used increased from 1.39 in heifers to 1.79 in first-parity cows and to 1.82 in second-parity cows, remaining relatively constant thereafter. In contrast, the mean calving difficulty PTA of the beef bulls used increased consistently with cow parity. Results from the present study demonstrate a clear difference in the mean acceptable genetic merit of beef AI bulls relative to dairy AI bulls but also indicates that these acceptable limits vary by herd characteristics.

Key words: dairy-beef, genetic, carcass, calving difficulty, sire selection

\section{INTRODUCTION}

As phenotypic reproductive performance in dairy females improves year-on-year (Berry et al., 2014), the necessity to generate replacement dairy females is reduced. This necessity is reduced further given both the pressures to reduce the environmental footprint of ruminants (Steinfeld et al., 2006) and the eroding available land base for dairy herd expansion (Jaeger and Schwick, 2014). Both pressures are contributing to a deceleration or even a reverse in dairy cow population growth. As a means to increase farm revenue, dairy producers are now, more than ever, considering the use of beef bulls on their dairy females in the pursuit of a more valuable calf. Berry et al. (2019) described a tool, what they termed a dairy-beef index, to rank beef bulls based on suitability for mating to dairy females; the goal of the risk-reward index was to rank bulls on estimated genetic potential to efficiently produce a high-value carcass with minimal repercussions on the milk, health, and reproductive performance of the dairy female. Although such an index is constructed with 
consideration of the relative economic merit of available animal-specific measures of genetic merit, there may be an inherent producer preference for either different bull credentials or different relative emphasis on the component traits. Depending on the farm system, some producers may impose independent culling levels for particular traits within the overall index when selecting bulls; restrictions may also be enforced on the reliability statistic associated with the estimate of genetic merit as a means of minimizing risk. From a survey of Irish dairy and beef farmers, Martin-Collado et al. (2017) demonstrated the maximum level of calving difficulty acceptable, signifying the importance of individual traits in bull choice. To this end, the choice of beef bull used by dairy producers is of interest, as is the way this choice may differ by herd type, crossbreeding strategy, and parity.

The objective of the present study was to compare the type of beef AI bulls used in dairy herds, with particular reference to traits associated with calving performance and carcass merit. The characteristics of the beef AI bulls used were compared with those of the dairy AI bulls used on the same farms, using the publicly available national genetic evaluations for these bulls before the insemination. The information generated will be useful in understanding the mind-set of dairy producers when selecting beef bulls and, by extension, inform advice systems that choose beef bulls for mating with dairy females.

\section{MATERIALS AND METHODS}

All cattle data used in the present study were sourced from the Irish Cattle Breeding Federation (http://www .icbf.com) national database. Predicted transmitting abilities (a measure of genetic merit equal to half the estimated breeding value of an animal) of individual traits for all animals from the last national genetic evaluation of the calendar years from 2013 to 2018, inclusive, were available. Because of the seasonal breeding system operational in Irish dairy herds (Berry et al., 2013), it is this last national genetic evaluation of the calendar year that is generally used when selecting dairy and beef bulls for use in dairy herds. Genetic evaluations were available for direct calving difficulty, direct gestation length, and direct perinatal calf mortality, as well as the carcass traits of carcass weight, conformation, and fat score. Reliability statistics (i.e., the accuracy of the genetic evaluation squared) were also available for all traits. All genetic evaluations are multi-breed, including all dairy and beef breeds; all PTA are expressed relative to a common base population and thus are comparable across breeds. No change in the genetic evaluation statistical models or base population occurred during the years considered here.

\section{Data}

A total of 2,862,360 AI records from 6,655 springcalving dairy herds between the years 2014 and 2019, inclusive, were available. All herds consisted of at least 40 cows, and only inseminations between March and July were considered, as this is typical of the breeding season of spring-calving herds in Ireland (Berry et al., 2013). Only AI to females with a major breed proportion represented by Holstein-Friesian, Jersey, Montbéliarde, Normande, or Norwegian Red (or some combination of such) were further considered; similarly, the only inseminations considered were to AI bulls that were one of the following breeds: Holstein-Friesian, Jersey, Montbéliarde, Normande, Norwegian Red, Aberdeen Angus, Aubrac, Belgian Blue, Charolais, Hereford, Limousin, Piedmontese, Parthenaise, Salers, or Simmental. Some do-it-yourself AI herds record only the last insemination per cow, and these herds were removed. Herd size was defined as the number of cows calving per year and was stratified into 75 or fewer, 76 to 105,106 to 155 , and more than 155 ; the thresholds were imposed to achieve a relatively equal number of herds per stratum. The percentage of the herd that was Holstein-Friesian $\times$ Jersey crossbred (the predominant crossbred) was stratified into $0 \%, 0.1$ to $50 \%, 50.1$ to $75 \%$, and more than $75 \%$, based on the number of cows calved. Parity was recoded as 0 (i.e., heifers), 1, 2, 3, 4, or $5+$. The proportion of females in the herd that were inseminated using a technician breeding service (as opposed to do-it-yourself) was stratified as less than 10\%, 10 to $90 \%$, and more than $90 \%$. Following all edits, $2,733,524$ insemination records from $1,936,691$ parities on 928,437 females from 18,073 herd-years and 5,967 herds were available. Each trait PTA and reliability for each service sire from the national genetic evaluation in the year immediately before the service was merged to the data set.

\section{Analysis}

Multiple regression linear fixed effects models were used to quantify the association between the dependent and independent variables. Dependent variables considered included the PTA of the AI bull for all traits as well as its respective reliability. Independent variables included the parity of the cow $(0,1,2,3,4$, or $5+)$, the percentage of the herd that was crossbred $(0 \%, 0.1$ to $50 \%, 50.1$ to $75 \%$, or more than $75 \%)$, herd size $(\leq 75$, 76 to 105,106 to 155 , or $>155$ cows), and the propor- 


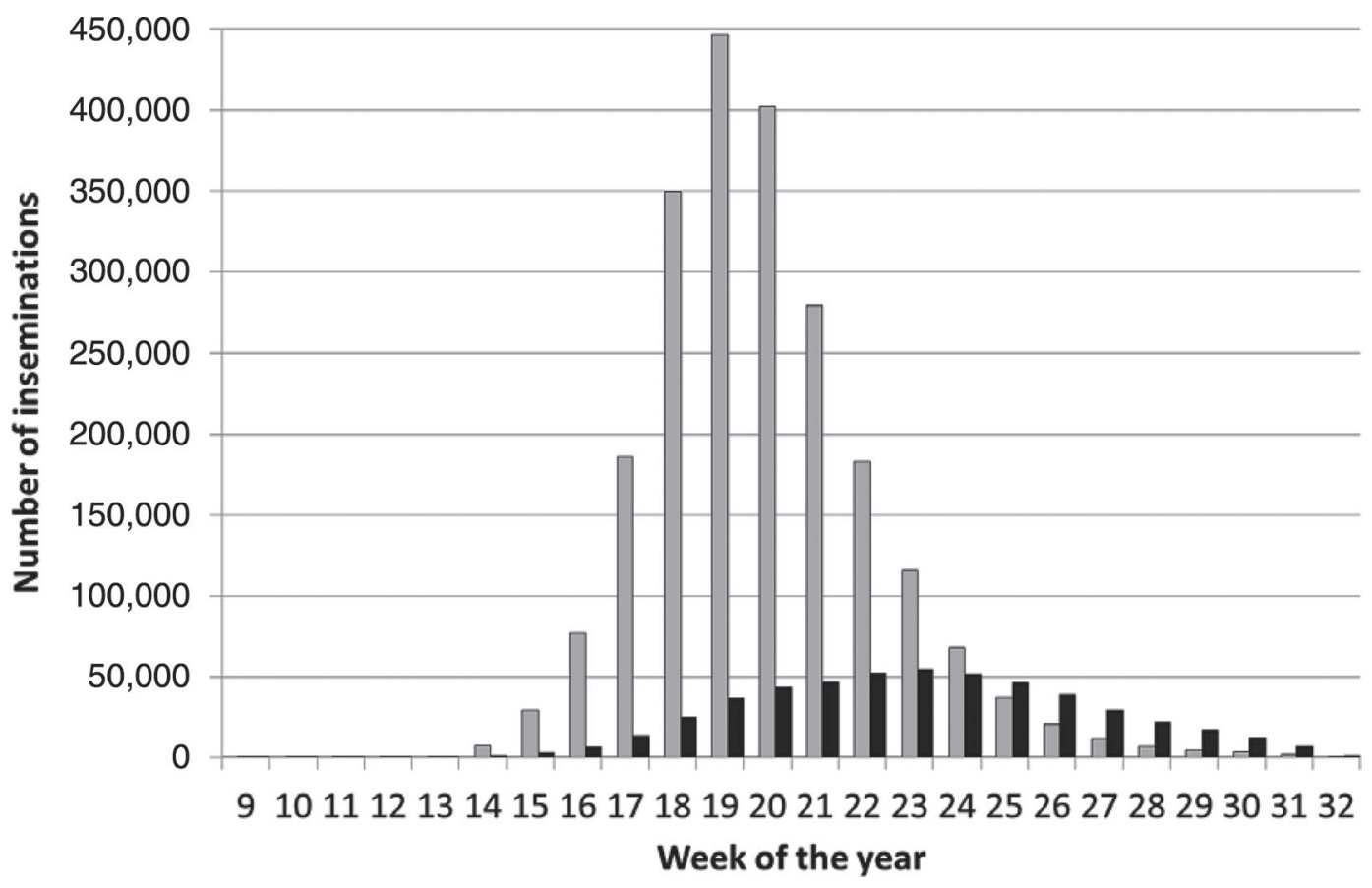

Figure 1. Distribution of dairy (gray bar) and beef (black bar) artificial inseminations in Irish herds by calendar week of the year.

tion of inseminations that were undertaken by technicians $(<10 \%, 10$ to $90 \%$, or $>90 \%)$. The least squares means for all factors were extracted from the analyses.

\section{RESULTS AND DISCUSSION}

The median numbers of dairy AI bulls and beef AI bulls used per herd-year were 11 and 3, respectively. The frequency distribution of inseminations to dairy and beef AI bulls by week of the calendar year is shown in Figure 1. Peak dairy insemination occurred at wk 19 (May 3 to May 9; 446,870 inseminations), whereas peak beef bull insemination occurred at wk 23 (May 31 to Jun. 6; 54,133 inseminations). This distribution is a function of the seasonal calving system operated by Irish dairy producers (Berry et al., 2013) to maximize the use of low-cost grazed grass in the diet of the cow. To maintain a seasonal calving system, producers attempt to generate their female dairy replacements from dams bred early in the breeding season. Not only should such dams be inherently fertile, which is an important attribute for seasonal-calving cows, but earlier breeding maximizes the chance of the virgin heifer being of sufficient age and weight at the time of breeding, ensuring she herself then calves early in the calving season. The importance of age at first calving in relation to a whole range of subsequent performance traits in dairy cattle has already been documented (Dobos et al., 2001; Berry and Cromie, 2009). Thus, with cows born earlier, producers maximize the chances of the heifer calving for the first time at the recommended 24 mo. Given the seasonal nature of breeding and calving in Irish dairy production systems (Berry et al., 2013), a delayed calving date, irrespective of parity, erodes farm profit (Shalloo et al., 2014). Because the mean calving interval for dairy females in Ireland is $379 \mathrm{~d}$ (Coffey et al., 2016), slippage in calving date will inevitably occur as the cow ages; thus, calving heifers at the start of the calving season minimizes the effect of slippage.

Once sufficient replacement females are deemed to have been generated, most dairy producers will tend to use beef bulls to maximize the subsequent calf value; in their analysis of calves from dairy herds sold at less than 42 d of age, McHugh et al. (2010) clearly demonstrated a superior value of beef $\times$ dairy cross male calves relative to dairy $\times$ dairy male calves. In their analysis of a national database of slaughtered cattle, Berry et al. (2018) also demonstrated a greater carcass value of beef (in this case, Angus) $\times$ dairy animals relative to dairy $\times$ dairy animals.

The breed of AI bulls used in dairy herds by parity is illustrated in Figure 2. On average, 68\% (parity 5 or higher) to $77 \%$ (parity 1) of all AI were to HolsteinFriesian bulls, with an additional 7 to $13 \%$ to other dairy breeds, which here included Jersey, Montbéliarde, Normande, and Norwegian Reds. The percentage of beef AI bulls used increased consistently by parity from $12 \%$ in heifers (parity 0 ) to $24 \%$ in cows of parity 5 or 


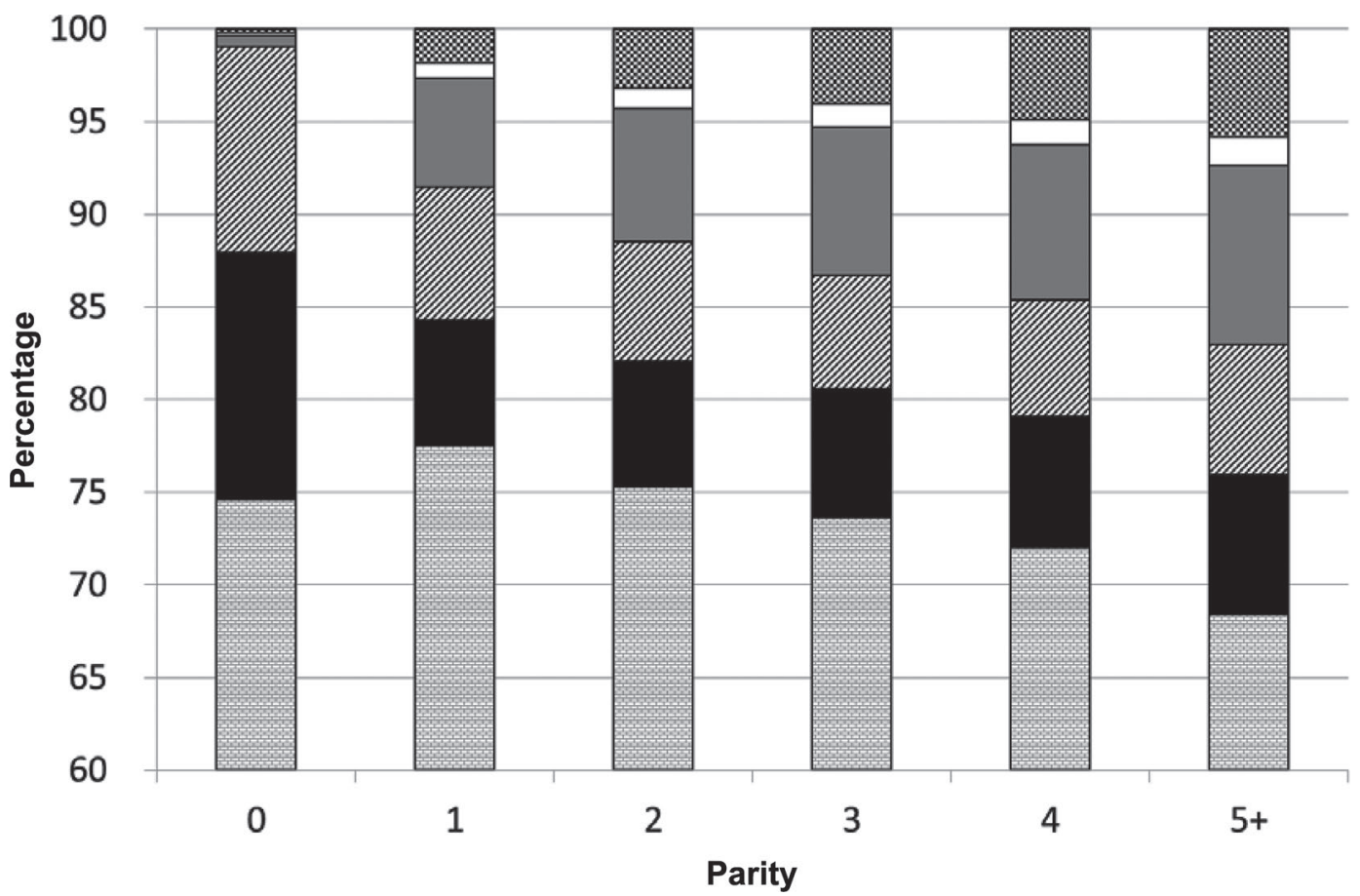

Figure 2. Percentage of inseminations by parity to Holstein-Friesian (brick pattern), other dairy (black), Aberdeen Angus (diagonal lines), Hereford (gray), Limousin (white), and other beef (checkered) bulls; at least $60 \%$ of all inseminations were to Holstein-Friesian bulls.

higher. The beef breed type used changed from predominantly Aberdeen Angus among younger females to predominantly Hereford among older females. The greater use of dairy bulls on younger females is not surprising, given that, if genetic gain is occurring on farm, then the younger females should, on average, be genetically superior, and thus genetic gain should be accelerated by using these as dams of dams. The Aberdeen Angus breed is traditionally renowned for its ease of calving, which is the rationale for why it was the predominant beef bull used on younger females, who, because of their smaller size and younger age, are more prone to requiring assistance at calving (Berry et al., 2007; Mee et al., 2011).

\section{Raw Means}

The weighted mean calving difficulty PTA of the beef AI bulls used in the dairy herds was 1.85 units higher (i.e., more difficult) than that of the dairy AI bulls used but with over 3 times more variability among the beef bulls (Table 1). All else being equal, this 1.85 units equates biologically to an expectation of 1.85 more dystocia events per 100 dairy females mated to beef bulls. Calving difficulty in Ireland is scored subjectively by producers on a 1 - to 4 -scale, where 1 represents no assistance, 2 represents some assistance, 3 represents severe assistance (i.e., dystocia), and 4 represents veterinary assistance; dystocia here represents scores 3 and 4. Calving difficulty is a known important consideration in the selection of bulls, especially for dairy farmers (Martin-Collado et al., 2017).

Calves sired by dairy bulls were expected to be born $3 \mathrm{~d}$ earlier than those of their beef counterparts mated on the same day, given the mean difference of $3 \mathrm{~d}$ in gestation length PTA between the dairy and beef AI bulls used. The shorter gestation length in dairy relative to beef bulls is well established (Fitzgerald et al., 2015). The weighted mean carcass weight PTA of the beef AI bulls used was $15 \mathrm{~kg}$ heavier than the dairy AI bulls, and the conformation score, which is measured on a scale of 1 to 15 (Englishby et al., 2016), was 1.71 units superior in the beef bulls. The superior conformation score of progeny from dairy herds sired by beef sires relative to those sired by dairy sires has already been established (Campion et al., 2009; Berry et al., 2018). The raw mean reliability of the beef bulls used was higher than that of the dairy bulls used for all traits, although it was more variable in the former. Minimal difference in genetic merit of the beef or dairy AI bulls was evident by whether or not the herd used extensive technician AI services and is therefore not discussed further.

The range in PTA of bulls used per breed is shown in Supplemental Table S1 (https://doi.org/10.3168/jds .2019-17430) for breeds with at least 100 bulls included 
Table 1. Weighted mean and SD for PTA and reliability of traits among dairy AI bulls $(2,229,890$ inseminations) and beef AI bulls (503,634 inseminations) used

\begin{tabular}{|c|c|c|c|c|}
\hline \multirow[b]{2}{*}{ Item } & \multicolumn{2}{|c|}{ Dairy } & \multicolumn{2}{|c|}{ Beef } \\
\hline & Mean & $\mathrm{SD}$ & Mean & $\mathrm{SD}$ \\
\hline \multicolumn{5}{|l|}{ PTA } \\
\hline Calving difficulty (\% difficult) & 1.87 & 0.84 & 3.72 & 2.59 \\
\hline Gestation length $(\mathrm{d})$ & -3.52 & 1.18 & -0.47 & 2.03 \\
\hline Mortality $(\%)$ & -0.17 & 0.64 & -0.23 & 0.43 \\
\hline Carcass weight $(\mathrm{kg})$ & -6.40 & 7.43 & 8.83 & 10.35 \\
\hline Carcass conformation (scale 1 to 15$)^{1}$ & -0.74 & 0.25 & 0.97 & 0.75 \\
\hline Carcass fat (scale 1 to 15$)^{1}$ & -0.28 & 0.17 & 0.31 & 0.59 \\
\hline \multicolumn{5}{|l|}{ Reliability } \\
\hline Calving difficulty & 73 & 24 & 79 & 30 \\
\hline Gestation length & 76 & 25 & 82 & 29 \\
\hline Mortality & 67 & 26 & 75 & 31 \\
\hline Carcass weight & 57 & 22 & 63 & 32 \\
\hline Carcass conformation & 54 & 22 & 58 & 34 \\
\hline Carcass fat & 53 & 23 & 57 & 35 \\
\hline
\end{tabular}

in the analysis. The Jersey bulls used had, on average, the best (i.e., easiest) PTA for calving difficulty, with the Belgian Blue being worse, followed by the continental breeds. The opposite was true, on average, for carcass conformation, but also, as expected (Albertí et al., 2008; Campion et al., 2009), the PTA for carcass weight of the continental bulls was best, whereas that of the dairy bulls, especially the Jersey, was worst. Nonetheless, large variability exists among breeds in the bulls used, with the worse PTA for calving difficulty in some Jersey bulls being better than the best PTA for calving difficulty in some of the continental beef breeds.

\section{Least Squares Means by Herd Size}

The least squares means for genetic merit and reliability of both dairy and beef AI bulls used in herds differing in size are shown in Table 2. Herd size was associated $(P<0.001)$ with all of the variables investigated. The percentage of all inseminations to beef AI bulls reduced as herd size increased; of all inseminations, $19 \%$ (cow herd size of 155 or more) to $30 \%$ (cow herd size 76 to 105) were bred to beef AI bulls. These statistics, however, as in the whole study, only relate to AI usage and do not consider natural matings that also occur in Irish dairy herds (Berry et al., 2013). The mean calving difficulty PTA of the dairy AI bulls decreased with increasing herd size, and although the mean calving difficulty PTA of the beef AI bulls increased with herd size from 75 or fewer cows to 155 cows, the largest herds (over 155 cows) used notably easier-calving beef bulls, albeit the mean PTA for direct calving difficulty was still twice that of the dairy bulls used in those herds (Table 2). Given the seasonal calving nature of
Irish dairy production systems (Berry et al., 2013), the calving period is extremely labor intensive, and this is naturally exaggerated in larger herds, although these herds sometimes have more than one labor unit. Nonetheless, minimizing the incidence of calving difficulty in larger herds contributes to easier and more timeefficient management, reducing the necessity for special care of cows injured during calving, at the expense of other farm chores. However, the trend of easier-calving beef AI bulls being used in larger herds was not necessarily mirrored in a preference for beef bulls with PTA for lighter carcasses (relative to the smallest herds), although the conformation score of the beef bulls favored by larger dairy herds was inferior. Although we found a general tendency for larger herds to use dairy AI bulls with lower reliability, this trend was not an obvious factor in the decision of what beef AI bulls to use. The former is likely an artifact of larger dairy herds using a great proportion of genomically tested AI bulls. Genomic evaluations for beef bulls in Ireland were only launched in 2016 (Berry et al., 2016).

\section{Least Squares Means by Extent of Herd-Level Crossbreeding}

The least squares means PTA and reliabilities of dairy and beef AI bulls used in herds differing in their uptake of Holstein-Friesian $\times$ Jersey crossbreeding are shown in Table 3. The extent of crossbreeding was associated $(P<0.001)$ with all traits evaluated. Irrespective of whether dairy or beef AI bulls were considered, herds that operated a more substantial crossbreeding breeding program (i.e., more than $50 \%$ crossbred cows) used, on average, easier-calving, shorter gestation-length bulls with lighter expected progeny carcasses of poorer 
Berry et al.: DAIRY-BEEF BULL CHOICES

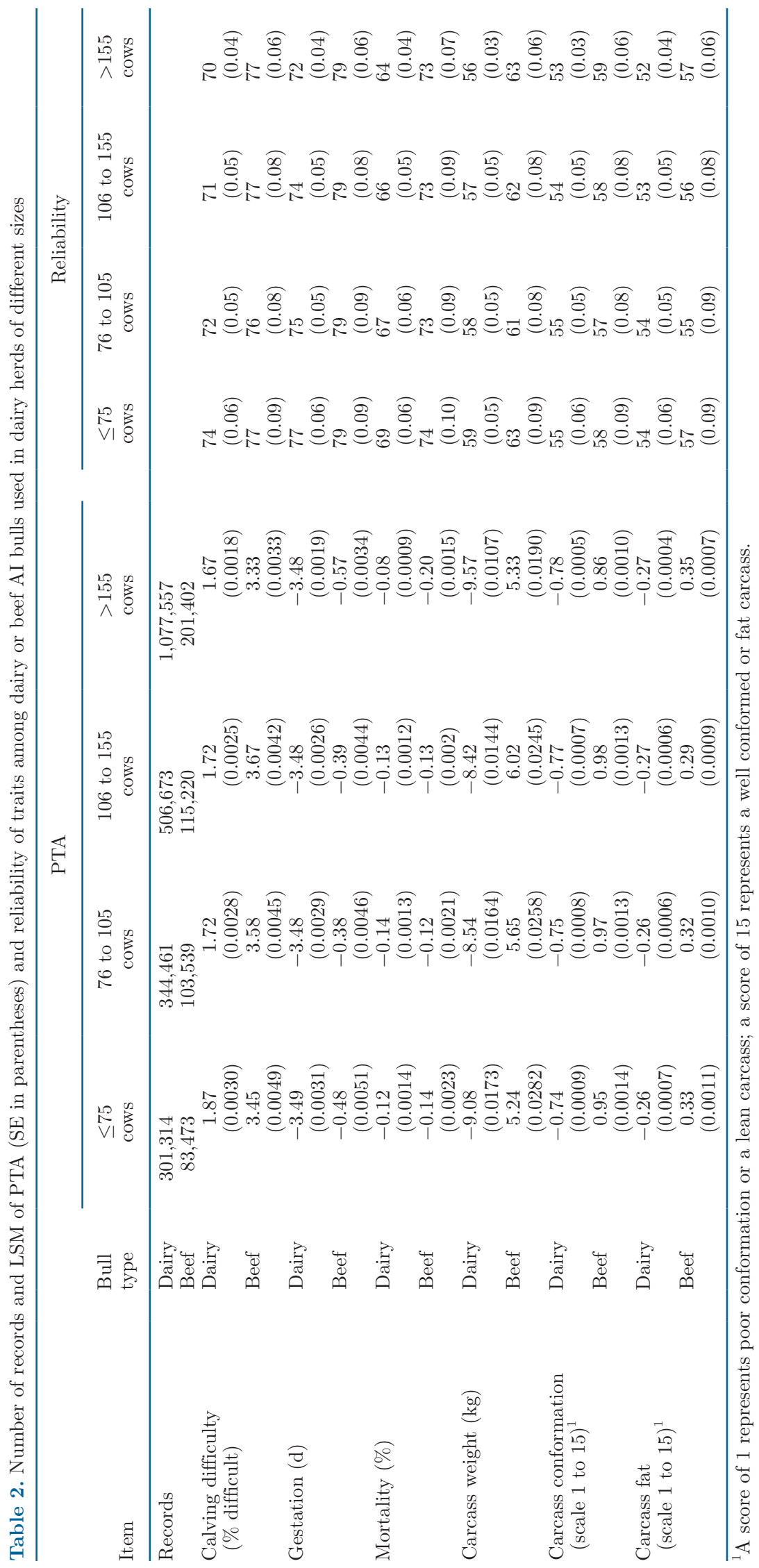


conformation. Although herds with more crossbreeding favored lower-reliability dairy bulls, no trend was observed in the reliability of the beef AI bulls used. Crossbreeding herds in Ireland are generally typified as being specialists in low-cost and efficient dairy production with, on average, less consideration on the revenue obtainable from beef. Crucial to the success of their business plan is that the cow achieves her peak milk yield with minimal perturbations; one such perturbation is calving difficulty (Berry et al., 2007; Berry et al., 2019), and thus the use of easy-calving bulls is a high priority for these producers. Given the genetic correlation between calving difficulty and carcass merit (Eriksson et al., 2004; Berry et al., 2019), the inferior carcass merit of the beef bulls used in crossbreeding herds is therefore also expected.

\section{Least Squares Means by Cow Parity}

The least squares means for genetic merit and associated reliability of dairy and beef AI bulls used by cow parity are presented in Table 4 . Cow parity was associated $(P<0.001)$ with all traits evaluated. Mean calving difficulty PTA of dairy AI bulls increased from 1.39 in heifers to 1.79 in first-parity cows and to 1.82 in second-parity cows but remained relatively constant thereafter. In contrast, the mean calving difficulty PTA of beef AI bulls used increased consistently with cow parity from 1.35 in heifers to 4.11 in cows of parity 5 and up. A similar trend was observed for gestation length, with the mean dairy bull PTA for gestation length getting longer from heifers to first- and secondparity cows but remaining constant thereafter, whereas mean PTA for gestation length for the beef AI bulls used lengthened incrementally with each increase in parity (Table 4).

Although minimal differences in PTA for either carcass weight or conformation were evident in the choice of dairy AI bulls used per parity, a trend was observed in that the beef AI bulls used had progressively heavier carcass weight PTA and superior carcass conformation PTA as the cow aged. An obvious trend existed for higher-reliability bulls, irrespective of whether dairy or beef bulls, to be used on heifers. The use of easiercalving bulls, regardless of breed, on virgin heifers is expected given the well-documented greater risk of dystocia in younger animals (Berry et al., 2007; Mee et al., 2011). Producers selecting bulls for use on heifers also obviously seek a greater degree of reassurance that the PTA of the bull chosen is as close to its true genetic merit as possible, as evidenced by the higher reliability of the bulls used on heifers relative to older cows; the effect was particularly noticeable for the PTA for calving difficulty, thus acting as a strategy to mitigate against a difficult calving in the female cohort that are naturally at a greater inherent risk (Mee, 2008).

\section{Potential Use of Results}

As herds expand, the available resources (labor, calving pens, calf pens, sick bays) per female will, on average, reduce. Such a trend contributes to a greater reliance on management and breeding decision support tools. One such decision support tool is that which advises on which bull to mate to which female; Carthy et al. (2019) outlined a mating advice tool for mating dairy bulls to dairy females based simply on maximizing the expected total merit index of the progeny while being cognizant of the expected inbreeding in the progeny and, at the same time, minimizing the expected progeny heterogeneity in the herd. A mating advice system could also be developed to advise on which beef bulls to mate to which dairy females. The algorithm could be populated with default parameters (e.g., minimize the probability of a resulting difficult calving) that could be overwritten by the user. Nonetheless, the population statistics estimated in this study provide a sound basis for deciding on such default parameters and how they can be tailored to the herd and individual cow.

The second main use of the results from the present study lies in the guidance to beef bull breeding programs for use on dairy females. Knowing the acceptable limits for traits such as calving difficulty and gestation length provides useful targets as to the tradeoff possible between traits affecting the dairy female (i.e., calving performance traits) and the traits influencing the revenue achievable for the calf (i.e., carcass traits). The latter is reflective of its acceptance by the beef industry as a suitable animal. This also has implications for the marketing of (natural mating) bulls. Bulls are currently marketed on breed, ancestry, and PTA for different traits, which is often accompanied by a statement of suitability for use on heifers. The information generated in the present study enables a greater granularity in the tailoring to end users for individual bulls, depending, for example, on factors such as herd size.

Knowledge of the incidence of calving difficulty in females at different parities is also useful in the derivation of economic values for calving difficulty. In their construction of an index to rank beef bulls for use on dairy females, Berry et al. (2019) calculated the economic value for calving difficulty on primiparous and multiparous cows separately, based on an underlying liability scale with thresholds imposed on the distribution based on the respective population mean. Amer et al. (2001) applied a similar approach in their estimation of economic value for calving ease in beef bulls for use on beef cows. 
Berry et al.: DAIRY-BEEF BULL CHOICES

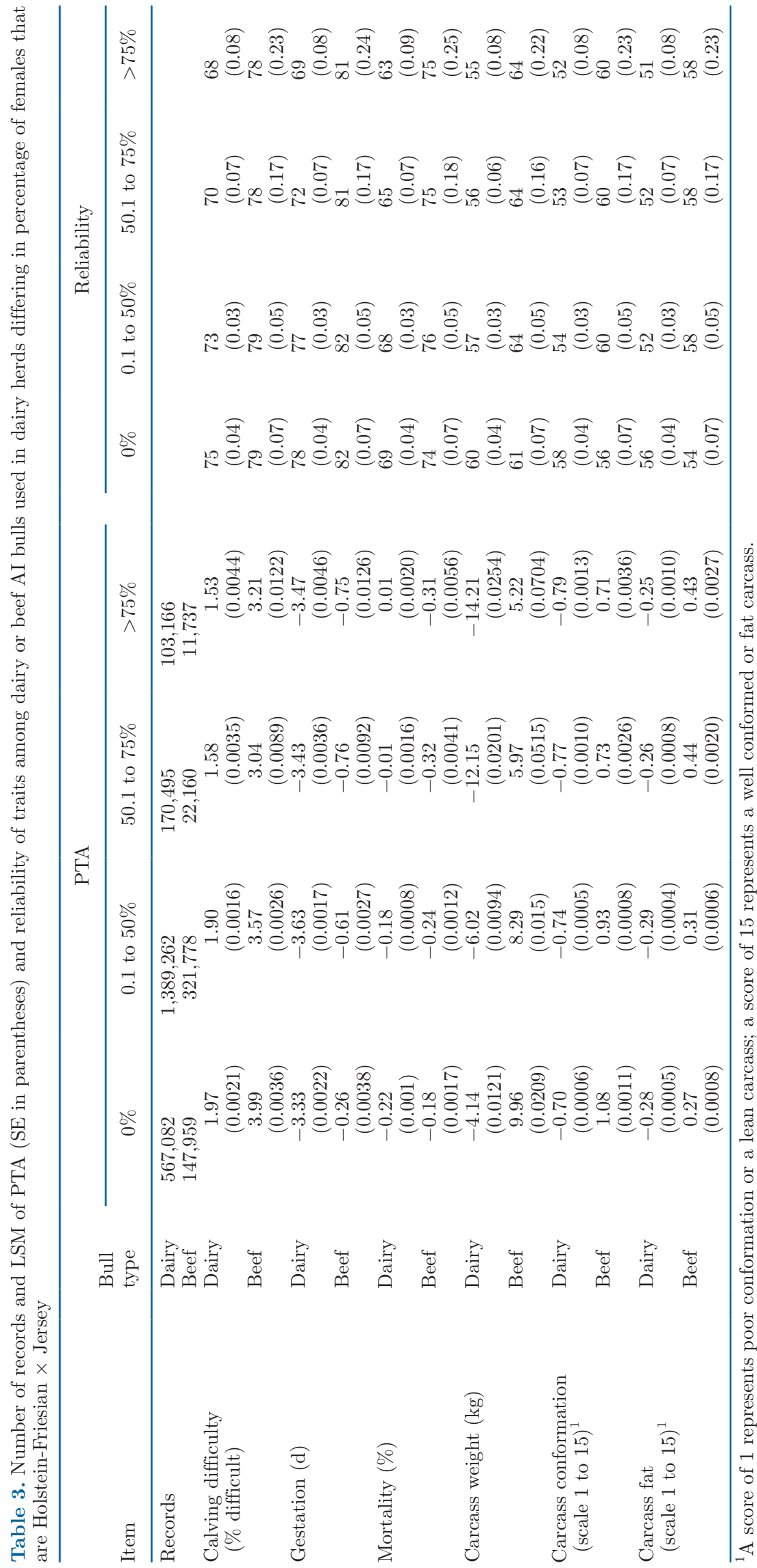




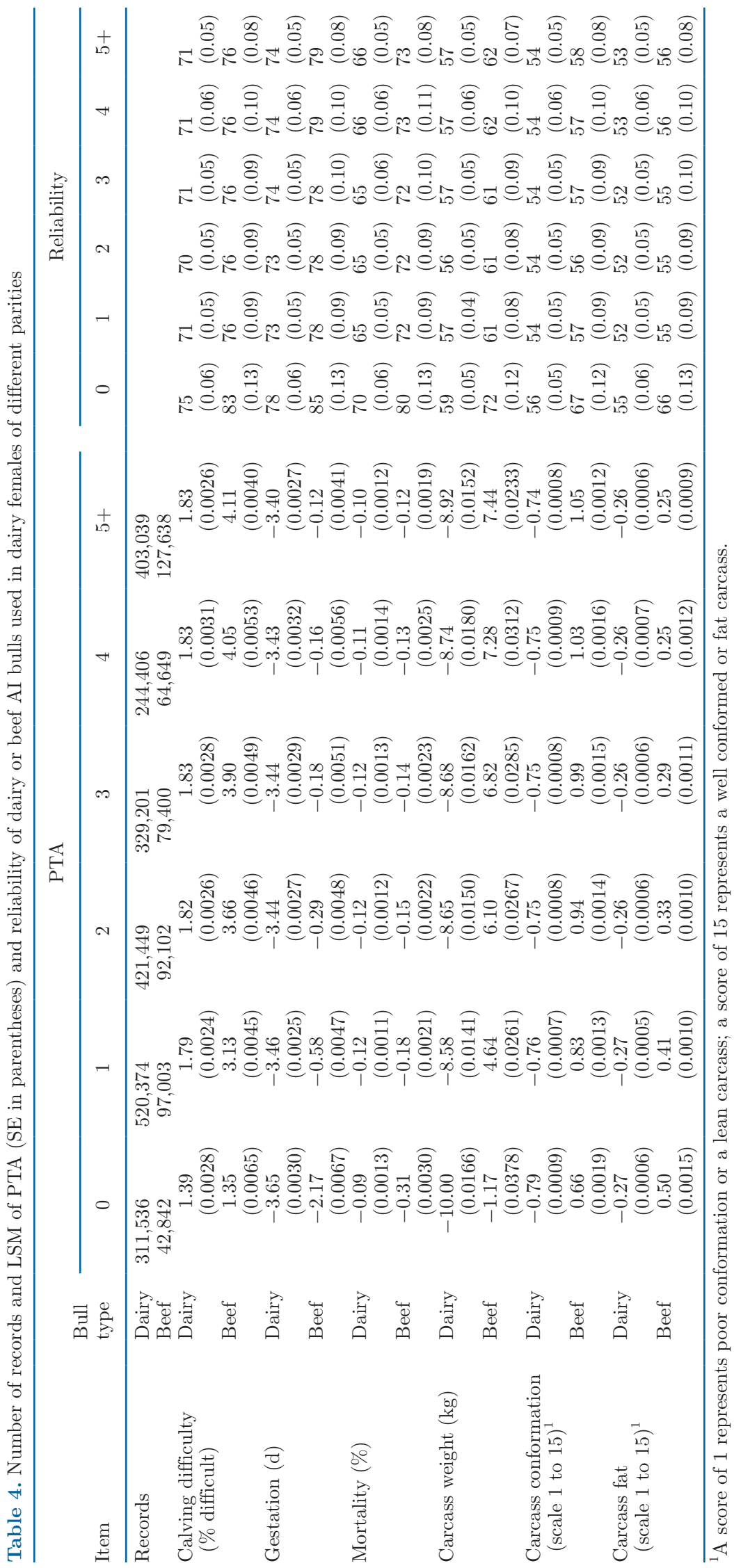




\section{CONCLUSIONS}

Although differences clearly existed between the mean genetic merit of individual traits of beef AI bulls and dairy AI bulls used on Irish dairy farms, the differential between the bull types also differed by herd characteristics, namely herd size and extent of crossbreeding. The calving difficulty PTA of the beef bulls used was 3.33 units versus 1.67 units for their dairy bull counterparts, although the differential was less in herds that practiced considerable crossbreeding as well as in both very small and very large herds. In fact, in heifers, the mean calving difficulty PTA of the beef bulls used was genetically easier-calving than their dairy counterparts, but the differential between the calving difficulty PTA of the beef bulls and dairy bulls widened (i.e., beef bulls were, on average, more difficult-calving than dairy bulls) as parity increased. Differences, in particular for genetic merit for carcass weight and carcass conformation, were also evident between the dairy and beef bulls used.

\section{ACKNOWLEDGMENTS}

This publication arose from research supported by a research grant from Science Foundation Ireland (Dublin) and the Department of Agriculture, Food and the Marine (Dublin) on behalf of the Government of Ireland under the Grant 16/RC/3835 (VistaMilk). The authors have not stated any conflicts of interest.

\section{REFERENCES}

Albertí, P., B. Panea, C. Sañudo, J. L. Olleta, G. Ripoll, P. Ertbjerg, M. Christensen, S. Gigli, S. Failla, S. Concetti, J. F. Hocquette, R. Jailler, S. Rudel, G. Renand, G. R. Nute, R. I. Richardson, and J. L. Williams. 2008. Live weight, body size and carcass characteristics of young bulls of fifteen European breeds. Livest. Sci. 114:19-30. https://doi.org/10.1016/j.livsci.2007.04.010.

Amer, P. R., G. Simm, M. G. Keane, M. G. Diskin, and B. W. Wickham. 2001. Breeding objectives for beef cattle in Ireland. Livest. Prod. Sci. 67:223-239. https://doi.org/10.1016/S0301-6226(00)00201-3.

Berry, D. P., P. R. Amer, R. D. Evans, T. Byrne, A. R. Cromie, and F. Hely. 2019. A breeding index to rank beef bulls for use on dairy females to maximize profit. J. Dairy Sci. 102:10056-10072. https:/ /doi.org/10.3168/jds.2019-16912.

Berry, D. P., and A. R. Cromie. 2009. Associations between age at first calving and subsequent performance in Irish spring calving Holstein-Friesian dairy cows. Livest. Sci. 123:44-54. https://doi .org/10.1016/j.livsci.2008.10.005.

Berry, D. P., J. F. Garcia, and D. J. Garrick. 2016. Development and implementation of genomic predictions in beef cattle. Anim. Front. 6:32-38. https://doi.org/10.2527/af.2016-0005.

Berry, D. P., M. J. Judge, R. D. Evans, F. Buckley, and A. R. Cromie. 2018. Carcass characteristics of cattle differing in Jersey proportion. J. Dairy Sci. 101:11052-11060. https://doi.org/10.3168/jds 2018-14992.

Berry, D. P., J. F. Kearney, K. Twomey, and R. D. Evans. 2013. Genetics of reproductive performance in seasonal calving dairy cattle production systems. Ir. J. Agric. Food Res. 52:1-16.
Berry, D. P., J. M. Lee, K. A. Macdonald, and J. R. Roche Jr.. 2007. Body condition score and body weight effects on dystocia and stillbirths and consequent effects on postcavling performance. J. Dairy Sci. 90:4201-4211. https://doi.org/10.3168/jds.2007-0023.

Berry, D. P., E. Wall, and J. E. Pryce. 2014. Genetics and genomic of reproductive performances in dairy and beef cattle. Animal 8(s1):105-121. https://doi.org/10.1017/S1751731114000743.

Campion, B., M. G. Keane, D. A. Kenny, and D. P. Berry. 2009. Evaluation of estimated genetic merit for carcass weight in beef cattle: Blood metabolites, carcass measurements, carcass composition and selected non-carcass components. Livest. Sci. 126:100-111. https://doi.org/10.1016/j.livsci.2009.06.003.

Carthy, T. R., J. McCarthy, and D. P. Berry. 2019. A mating advice system in dairy cattle incorporating genomic information. J. Dairy Sci. 102:8210-8220. https://doi.org/10.3168/jds.2019-16283.

Coffey, E. L., B. Horan, R. D. Evans, and D. P. Berry. 2016. Milk production and fertility performance of Holstein, Friesian, and Jersey purebred cows and their respective crosses in seasonal-calving commercial farms. J. Dairy Sci. 99:5681-5689. https://doi.org/10 .3168/jds.2015-10530.

Dobos, R. C., K. S. Nandra, K. Riley, W. J. Fulkerson, I. J. Lean, and R. C. Kellaway. 2001. Effects of age and liveweight at first calving on first lactation milk, protein and fat yield of Friesian heifers. Aust. J. Exp. Agric. 41:13-19. https://doi.org/10.1071/EA00090.

Englishby, T. M., G. Banos, K. L. Moore, M. P. Coffey, R. D. Evans, and D. P. Berry. 2016. Genetic analysis of carcass traits in beef cattle using random regression models. J. Anim. Sci. 94:1354-1364. https://doi.org/10.2527/jas.2015-0246.

Eriksson, S., A. Nasholm, K. Johansson, and J. Philipsson. 2004. Genetic relationships between calving and carcass traits for Charolais and Hereford cattle in Sweden. J. Anim. Sci. 82:2269-2276. https: //doi.org/10.2527/2004.8282269x.

Fitzgerald, A. M., D. P. Ryan, and D. P. Berry. 2015. Factors associated with differential in actual gestational age and gestational age predicted from transrectal ultrasonography in pregnant dairy cows. Theriogenology 84:358-364. https://doi.org/10.1016/j .theriogenology.2015.03.023.

Jaeger, J. A. G., and C. Schwick. 2014. Improving the measurement of urban sprawl: Weighted Urban Proliferation (WUP) and its application to Switzerland. Ecol. Indic. 38:294-308. https://doi.org/ 10.1016/j.ecolind.2013.11.022

Martin-Collado, D., F. Hely, T. J. Byrne, R. D. Evans, A. R. Cromie, and P. R. Amer. 2017. Farmer views on calving difficulty consequences on dairy and beef farms. Animal 11:318-326. https://doi org $/ 10.1017 /$ S1751731116001567.

McHugh, N., A. G. Fahey, R. D. Evans, and D. P. Berry. 2010. Factors associated with selling price of cattle at livestock marts. Animal 4:1378-1389. https://doi.org/10.1017/S1751731110000297.

Mee, J. F. 2008. Prevalence and risk factors for dystocia in dairy cattle: A review. Vet. J. 176:93-101. https://doi.org/10.1016/j.tvjl .2007.12.032.

Mee, J. F., D. P. Berry, and A. R. Cromie. 2011. Risk factors for calving assistance and dystocia in pasture-based Holstein-Friesian heifers and cows in Ireland. Vet. J. 187:189-194. https://doi.org/ 10.1016/j.tvjl.2009.11.018.

Shalloo, L., A. R. Cromie, and N. McHugh. 2014. Effect of fertility on the economics of pasture-based dairy systems. Animal 8(Suppl. 1):222-231. https://doi.org/10.1017/S1751731114000615.

Steinfeld, H., P. Gerber, T. Wassenaar, V. Castel, M. Rosales, and C. de Haan. 2006. Livestock's Long Shadow. Food and Agriculture Organization of the United Nations. Accessed Mar. 8, 2012. http: //www.fao.org/docrep/010/a0701e/a0701e00.htm.

\section{ORCIDS}

D. P. Berry (ํ) https://orcid.org/0000-0003-4349-1447 